\title{
THE PHYSICAL AND MENTAL DEVELOPMENT OF CHILDREN WITH CONGENITAL HEART DISEASE
}

BY

\author{
MAURICE CAMPBELL, O.B.E., D.M., F.R.C.P., and GEOFFREY REYNOLDS, B.M., B.Ch.. \\ (From the Cardiac Department, Guy's Hospital, London)
}

Many children with congenital heart disease are obviously thin and under weight and some are small for their age. This has been commented on by many writers but there are few studies of any large series.

Benn (1947) has analysed statistically the height and weight of school children with patent ductus arteriosus. He found both boys and girls were under weight, the differences for the boys being probably, and for the girls certainly, of statistical significance. The increased height of the girls also seemed to be of statistical significance. In auricular septal defect, under-development and small build were emphasized by Roesler (1934) but were not found by Bedford, Papp, and Parkinson (1941) in adults.

This under-development is not true of all forms of congenital heart disease. The good physique of many cases of coarctation of the aorta has been referred to by several recent writers (Perlman, 1944: Bramwell, 1947; and Newman, 1948, for example). We are unaware of any series of measurements and weights, though there can be no doubt about the good physique and sometimes athletic prowess of many patients with coarctation.

Following the visit of Blalock to Guy's Hospital in September, 1947, and his demonstrations of the surgical treatment of Fallot's tetralogy, and the successful continuation of this work by Brock (Baker, Brock, Campbell, and Suzman, 1949), large numbers of patients with congenital heart disease have been examined to select those suitable for operation. Enough of these have now been seen to allow conclusions to be drawn regarding some aspects of physical development in this condition. Difficulties in making a clinical diagnosis of the exact lesion mean that conclusions about differences between individual types of lesion are on a less sure foundation than those between congenital heart lesions as a whole and the normal.

\section{Sex and Age Distribation}

The height and weight of the first 200 cases, for which our records were complete, have been analysed. The sex and age distribution of these and the preliminary clinical diagnosis made are shown in table 1 . The figures are substantially the

TABLE 1

AGE, SEX, AND DIAGNOSIS OF 200 CASES OF CONGENITAL HEART DISEASE

\begin{tabular}{|c|c|c|c|c|c|c|}
\hline & $\begin{array}{l}\text { Age } \\
\text { in years }\end{array}$ & $0-4$ & $5-9$ & $10-14$ & $15-35$ & Total \\
\hline & Male & 43 & 28 & 27 & 13 & 111 \\
\hline \multirow[t]{4}{*}{ Sex } & Female & 27 & 27 & 25 & 10 & 89 \\
\hline & Total & 70 & 55 & 52 & 23 & 200 \\
\hline & $\begin{array}{l}\text { Fallot's } \\
\text { tetralogy }\end{array}$ & 23 & 27 & 26 & 11 & 87 \\
\hline & $\begin{array}{l}\text { Possible } \\
\text { Fallot }\end{array}$ & 15 & 4 & 1 & 2 & 22 \\
\hline \multirow[t]{3}{*}{ Lesion } & *`Fallot + & 3 & 1 & 5 & 1 & 10 \\
\hline & $\begin{array}{l}\text { Other } \\
\text { lesions }\end{array}$ & 29 & 23 & 20 & 9 & 81 \\
\hline & Total & 70 & 55 & 52 & 23 & 200 \\
\hline
\end{tabular}

- 'Fallot -' has been used as an abbreviation for patients who have the general picture of Fallot's tetralogy, plus some other physical sign indicating an additional lesion.

same as for the first 340 cases. The proportions were about six boys for each five girls. The numbers in each five-year period fell, and if the numbers were plotted by years the fall was seen to be sharpest from about seven to fourteen years and then more gradual, partly because the smaller number of patients surviving after fifteen years of age have presumably less defective hearts and a longer life is possible. As regards the diagnosis, perhaps more cases should have been moved from 'Fallot's tetralogy' to the doubtful group. Many of this latter group were infants, in whom more certain diagnosis is often not possible. "Fallot + ' has been used as a convenient abbreviation in some of the tables for Fallot's tetralogy plus some physical sign that indicates an additional lesion. In eight of the cases of 'Fallot + ' signs suggesting a patent ductus 
arteriosus were present in addition, and there was also coarctation of the aorta in one of these; one case had aortic incompetence, and one was thought to have congenital aortic stenosis.

The 'other lesions' included such varied groups as tricuspid atresia with a non-functioning right ventricle, pulmonary valvular stenosis with or without a patent foramen ovale, and transposition of the aorta and pulmonary artery with a septal defect, as well as cases in which no diagnosis was made. These groups were thought to be too small for individual statistical treatment.

\section{Height}

The heights of the patients are plotted in fig. 1 . The average normal curves between five and fourteen years are those for London County Council school children in 1938 (Menzies, 1939). No comparable figures for ages above and below this could be found, the lines below five years being adopted from Holt (1940) and those above fourteen years following Cruikshank (1946). Only thirtyfour of these $\mathbf{2 0 0}$ children are an inch or more above this average height, whereas 124 are the same amount below it. Their average is 96.4 per cent. of average normal, or about 1 in. below normal for a child of one year, and $2 t$ in. below for an adult.

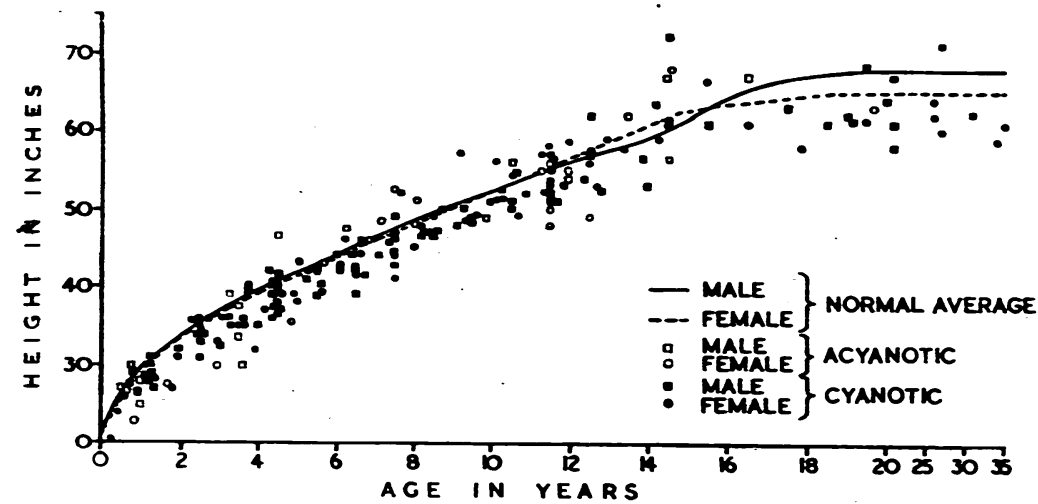

FrG. 1.-Relationship of height and age in congenital heart disease. It will be seen that most of the cyanotic cases are below the line indicating the normal average, but not greatly, the average being only 3 per cent. below.

\section{Fallot's}

tetralogy

Possible

Fallot's and

'Fallot's +'

Other lesions

$97 \cdot 1$ one-quarter, were reported to have slight cyanosis on exertion or sometimes in very cold weather. We feel that in this border line group it is difficult to exclude peripheral cyanosis and for this reason, among others, such patients are better omitted from the definite cyanotic group.

TABLE 2

PERCENTAGE OF AVERAGE NORMAL HEIGHT OF 200 CASES OF CONGENITAL HEART DISEASE

\begin{tabular}{ccc}
$\begin{array}{c}\text { Divided by } \\
\text { lesion }\end{array}$ & Total & $\begin{array}{c}\text { Divided by } \\
\text { cyanosis }\end{array}$ \\
\hline Lesion & $\begin{array}{c}\text { Percentage of average } \\
\text { normal height }\end{array}$ & Cyanosis
\end{tabular}

$94 \cdot 0$

Severe

A similar classification was made as regards disability. 'Severe' disability means that the patient was able to walk very little and was made dyspnoeic by a short distance, such as 50 yards.

In general, the greater the degree of cyanosis the greater the effect on the growth of the patient (table 2).

The average height in the acyanotic group was nearly 98 per cent. of the normal, but in those with severe cyanosis it was only 94 per cent. For a given degree of cyanosis, however, those with Fallot's tetralogy were, on the average, not so small as those with other lesions (table 3).

The patients were classified by their cyanosis on the following scale.

Grade 1. Cyanosis on exertion only.

Grade. 2. Cyanosis always present, but not very obvious at a glance.

Grade 3. Cyanosis moderately severe at rest and obvious at a gtance.

Grade 4. Cyanosis gross at rest.

'Severe' cyanosis in this paper means those cases placed in grade 4 and between 3 and 4 , and 'moderate' cyanosis, those in grades 3 and 2. It will be seen that the acyanotic group are not all strictly acyanotic, as a proportion of them, about
Statistically the difference between the heights of those with Fallot's tetralogy and those with other cyanotic lesions is significant, being 2.86 times its standard error, that is being liable to occur by chance only once in 240 times (table 4). The differences between the two groups of severe and moderate cyanosis which make up these larger groups are also probably significant, though in the former the numbers are too small and in the latter the difference falls just below the conventional figure of twice its standard error (table 4).

Even if those cases with acyanotic lesions are included, and they accounted for nearly half of the 
TABIE 3

COMPARISON BETWEEN HEIGHT OF COMPARABLY CYANOSED CASES WITH FALLOTS TETRALOGY AND OTHER LESIONS

\begin{tabular}{|c|c|c|c|c|c|c|}
\hline Lesion & Cyanosis & No. of Cases & & Percentage of Average & Normal & Height \\
\hline \multirow{3}{*}{ Fallot's tetralogy } & Severe & 18 & $96 \cdot 3$ & 7 & & \multirow{3}{*}{$97 \cdot 1$} \\
\hline & Moderate & 69 & & $97 \cdot 3\}$ & & \\
\hline & Nil & $\mathbf{0}$ & & & $-j$ & \\
\hline \multirow{3}{*}{ Other lesions } & Severe & 10 & $91 \cdot 5$ & $?$ & & \multirow{3}{*}{96.0} \\
\hline & Moderate & 33 & & $95 \cdot 4$ & & \\
\hline & Nil & 38 & & & 97.8 & \\
\hline
\end{tabular}

other lesions, those with Fallot's tetralogy still average nearer normal height than all the other lesions combined, though this difference is not sufficient to be statistically significant (table 4). This probably corresponds with the relatively good prognosis of Fallot's tetralogy compared with that of many other cyanotic lesions. Thus the average height of eleven cases of tricuspid atresia, a condition that clinically resembles Fallot's tetralogy closely but carries so much worse a prognosis, was only 94 per cent. of normal compared with an average height of eighty-seven cases of Fallot's tetralogy of 97 per cent.

\section{Weight}

The weights of these 200 patients are plotted in fig. 2 , the curve of average normal being obtained as in fig. 1. Only one-tenth (19 out of the 200) are $2 \mathrm{lb}$. or more above this average, whereas eighttenths (157) are this much below it. If a normal height to weight ratio were to be maintained an average weight of about 92 per cent. of average normal (varying between 90 and 94 per cent. in different age groups) would be expected for an average height of $\mathbf{9 6 . 4}$ per cent. of normal. In fact their weights average only 85 per cent. of average normal.

A large majority of these patients are more under weight than they are below normal height, and this is well shown in fig. 3 in which height is plotted against weight. The curve of average normal is plotted from the figures for average normal for males used in figs. 1 and 2. The curve for females lies so close to this that it has been omitted. As age increases in these patients weight comes to depend progressively more on age and less on height, so that only the weights of those below twenty years of age have been plotted. In this figure only 16 patients are more than $2 \mathrm{lb}$. above the normal weight for their actual height, whereas 138

TABLE 4

STATISTICAL SIGNIFICANCE OF DIFFERENCES IN HEIGHT

\begin{tabular}{|c|c|c|c|c|c|}
\hline Cyanosis & Lesion & $\begin{array}{l}\text { Percentage of } \\
\text { normal height }\end{array}$ & $\begin{array}{l}\text { Standard } \\
\text { deviation }\end{array}$ & $\begin{array}{l}\text { Standard } \\
\text { error }\end{array}$ & Significance* \\
\hline \multirow[t]{2}{*}{ All grades } & Fallot & $97 \cdot 1$ & $\pm 5 \cdot 0$ & $\pm 0 \cdot 54$ & \multirow{2}{*}{$2 \cdot 86$} \\
\hline & Other & $94 \cdot 5$ & $\pm 4 \cdot 85$ & $\pm 0 \cdot 74\}$ & \\
\hline \multirow[t]{2}{*}{ Severe } & Fallot & $96 \cdot 3$ & $\pm 4 \cdot 31$ & $\pm 1 \cdot 08\}$ & \multirow{2}{*}{$2 \cdot 31$} \\
\hline & Other & $91 \cdot 5$ & \pm 5.61 & $\pm 1 \cdot 77$ & \\
\hline \multirow[t]{2}{*}{ Moderate } & Fallot & $97 \cdot 3$ & $\pm 5 \cdot 13$ & $\pm \mathbf{0 . 6 2}$ & \multirow{2}{*}{1.95} \\
\hline & Other & $95 \cdot 4$ & $\pm 4 \cdot 31$ & $\pm 0 \cdot 75\}$ & \\
\hline \multicolumn{2}{|c|}{ Fallot's tetralogy (all cases) } & $97 \cdot 1$ & $\pm 5 \cdot 0$ & $\pm 0 \cdot 54$ & \multirow[b]{2}{*}{$1 \cdot 13$} \\
\hline \multicolumn{2}{|c|}{$\begin{array}{l}\text { All other cases including } \\
\text { acyanotic }\end{array}$} & $96 \cdot 0$ & $\pm 7 \cdot 3$ & $\pm 0.81 \mathrm{j}$ & \\
\hline
\end{tabular}

- The difference of the means divided by the square root of the sum of the squares of the standard errors. Figures over 2 may be taken as significant. 
are more than $2 \mathrm{lb}$. below it. Almost all these children were, therefore, under the average weight not only for their age but also for their height.

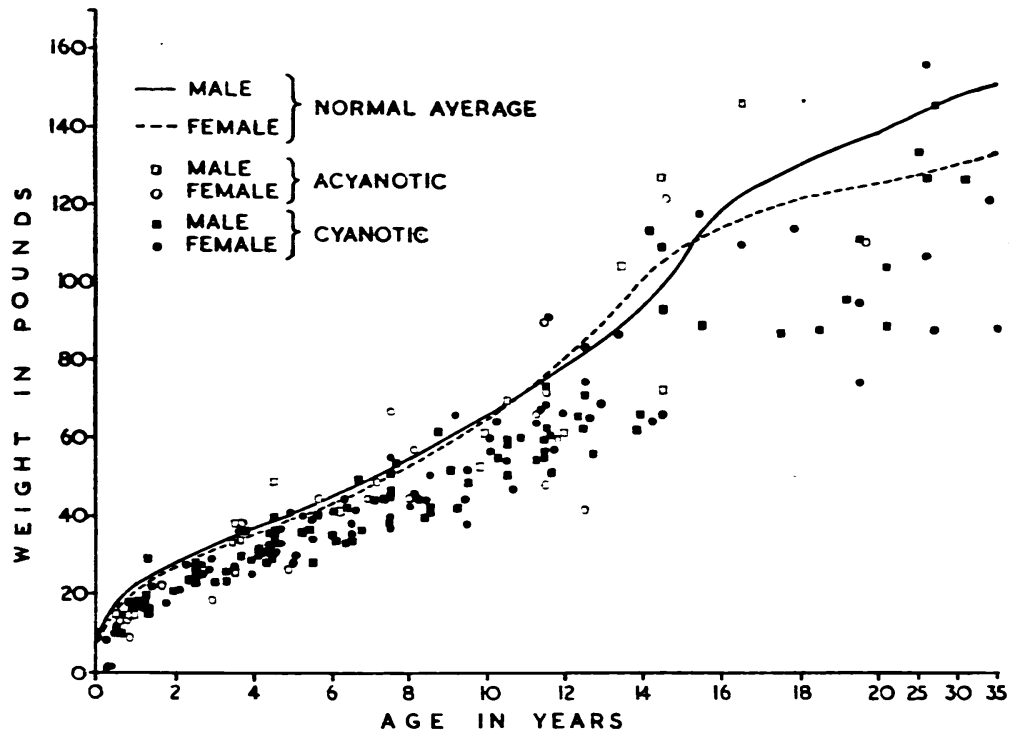

FIG. 2.-Relationship of weight and age in congenital heart disease. $A$ few of the acyanotic cases are above weight, but this is exceptional with the cyanotic cases and many are considerabiy below weight, much more so than as regards height, the average deficiency being 15 per cent.

As in the case of height, there is some correspondence between the degree of cyanosis and underweight (table 5), those without cyanosis being nearly 91 per cent. and those with severe cyanosis being under 77 per cent. of average normal weight. But those with Fallot's tetralogy are less affected than those with other lesions (table 6), the relative figures for Fallot's tetralogy and for other lesions being 80 and 73 for severely cyanotic and 89 and 80

TABLE 5

PERCENTAGE OF AVERAGE NORMAL WEIGHT OF 200 CASES OF CONGENITAL HEART DISEASE

\begin{tabular}{|c|c|c|c|c|}
\hline \multirow{2}{*}{$\begin{array}{c}\begin{array}{c}\text { Divided by } \\
\text { lesion }\end{array} \\
\text { Lesion }\end{array}$} & & & & $\begin{array}{l}\text { Divided by } \\
\text { cyanosis }\end{array}$ \\
\hline & \multicolumn{3}{|c|}{$\begin{array}{c}\text { Percentage of average } \\
\text { normal weight }\end{array}$} & Cyanosis \\
\hline $\begin{array}{l}\text { Fallot's } \\
\text { tetralogy }\end{array}$ & $87 \cdot 2$ & & $-76 \cdot 9$ & Severe \\
\hline $\begin{array}{l}\text { Possible } \\
\text { Fallot and } \\
\text { "Fallot }+ \text {, }\end{array}$ & $81 \cdot 7\}$ & $85 \cdot 1$ & $85 \cdot 6$ & Moderate \\
\hline Other lesions & $84 \cdot 1 \mathrm{~J}$ & & 90.7 & Nil \\
\hline
\end{tabular}

respectively for moderately cyanotic cases. The figure for thirteen cases of tricuspid atresia, not all of whom are included above, was 78. It appears, therefore, that cyanosis alone is not responsible for the under-development of these children. Another factor, as pointed out by Taussig (1947), may be a left to right shunt reducing the volume of the systemic circulation, such as occurs in patent ductus arteriosus, auricular septal defect, transposition of the great vessels, but this left to right shunt is not present in Fallot's tetralogy.

The mothers were almost unanimous in complaining about the difficulty of making their children eat. But in addition to an absence of fat, the extremely poor muscular development, made worse by the absence of any normal exercise, must add to the deficiency in weight.

\section{Age of Walling}

As the degree of physical development may be less than that of normal children, so may the rate of this be retarded

TABLE 6

COMPARISON BETWEEN WEIGHT OF COMPARABLY CYANOSED CASES WITH FALLOTS TETRALOGY AND OTHER LESIONS

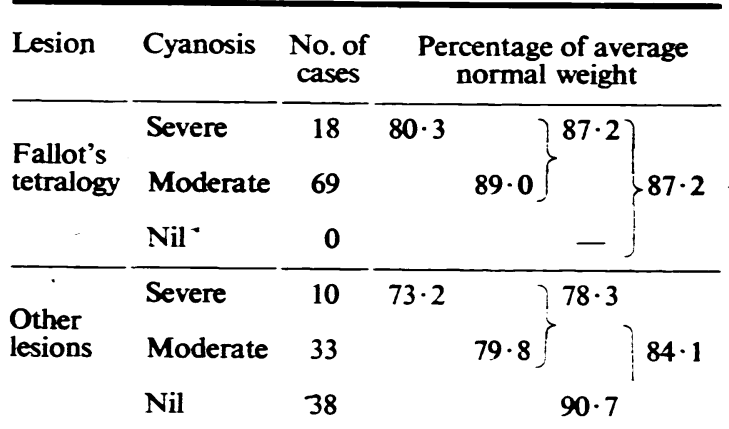

and the milestones of infancy reached late. Thus, of a total of 294 patients, only 52 per cent. were walking by the age of eighteen months, and 73 per cent. by two years. But whereas out of forty-nine patients who were not cyanosed, 76 per cent. were walking by eighteen months and 92 per cent. by two years (figures probably not much 
below those for normal children) corresponding percentages for 245 cyanotic patients were only 47 and 69 per cent. respectively. Only 60 per cent.

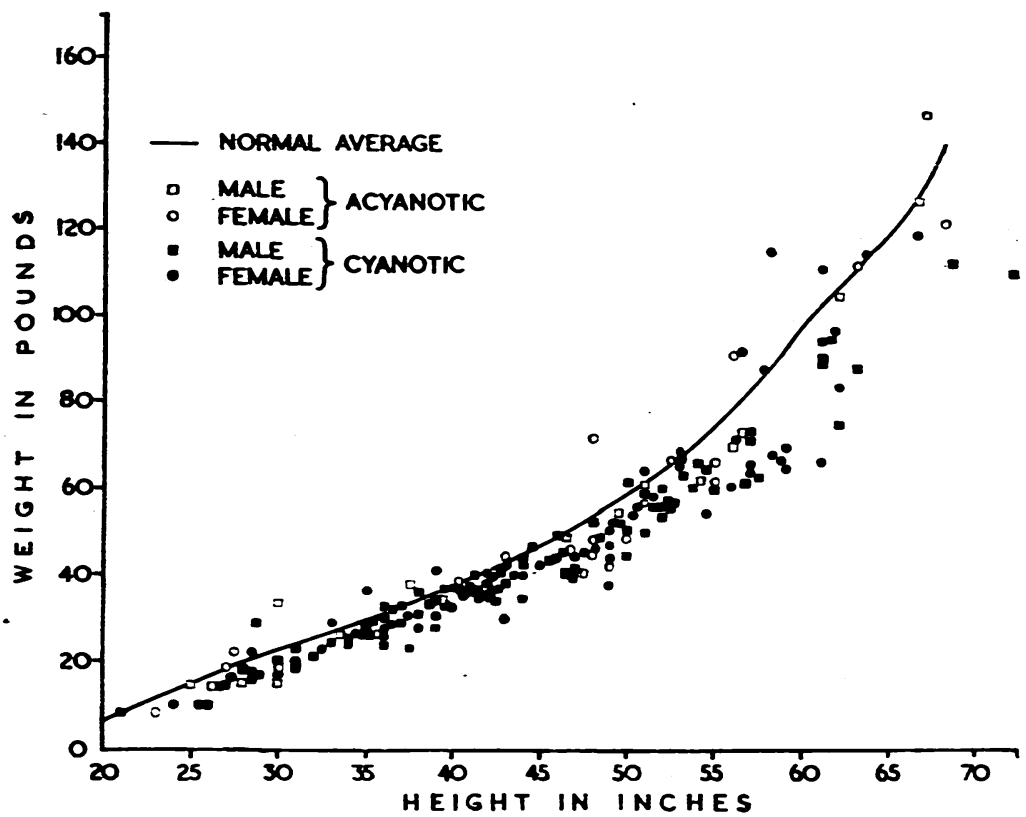

FIG. 3.-Relationship of height and weight in congenital heart disease. The normal curve is taken from the average normals of figs. 1 and 2 . This shows in another form that the weight is much more reduced than the height as the result of cyanotic congenital heart disease.

of those severely cyanosed were walking by two years, and only 47 per cent. of those in whom severe cyanosis dated from birth (table 7, columns 4 and 6 ).

This correlation makes it reasonable to infer that cyanosis or presumably the reduction in the normal oxygen saturation of the blood is one of the factors responsible for the lateness in walking. But the poor muscular development may itself be partly responsible and these two will react on each other, the muscles failing to get the stimulus to further development that walking would normally produce.
Although we show that walking is somewhat delayed in many severely cyanotic cases, we would emphasize that great delay is unusual. Case 0015 did not walk till he was seven years old, but no one who saw him when he was nineteen and only able to walk 30 yards thought him mentally backward. His quick progress after operation (within a few months he was able to walk six miles, to join in the activities of a boy scout camp, and to get engineering work) was further evidence of this. There were few cases as delayed as this. Much backwardness should lead to a careful examination of the patients' mental condition and a search for other possible causes.

Mental Development and Age of Talking

Mental development, except in those with actual mental defect, appears on the whole to be normal. Most of the children are bright and intelligent, and the lack of schooling which their physical disability may cause is often overcome by the ready way in which they profit from instruction at home or simply from the close contact with adults which their disability makes necessary.

In assessing the rate of development, the age at which these patients talk has been noted. The definition of this admittedly rather indefinite time was left to the parents. The details are given in table 7 and a glance at the last four columns shows the main contrasts. In columns 5 and 7 dealing with talking the percentages only fall slowly, if at all, till the last line dealing with those with severe

TABLE 7

PERCENTAGE OF CASES WITH VARIOUS DEGREES OF CYANOSIS, WALKING AND TALKING AT EIGHTEEN MONTHS AND AT TWO YEARS

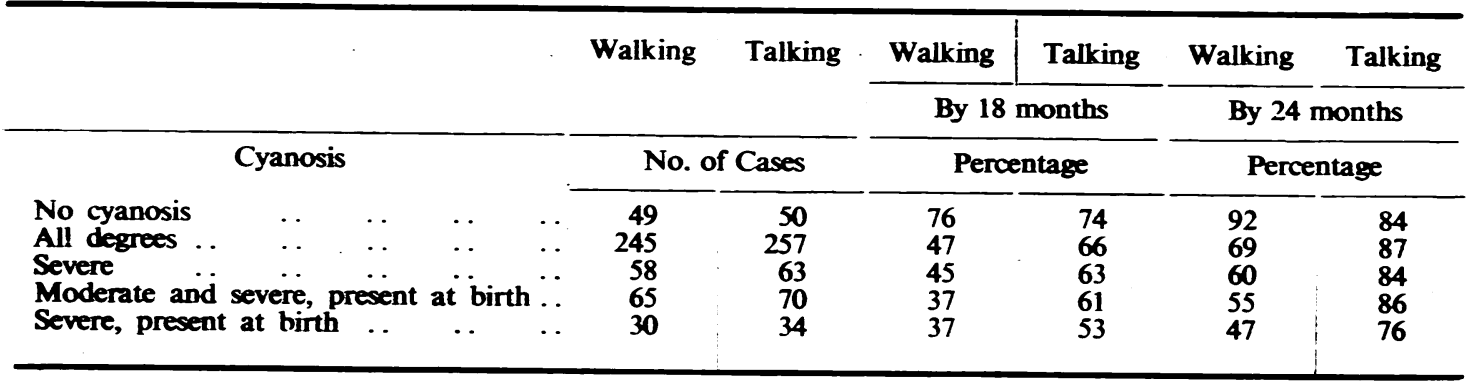


cyanosis that had been present from birth. Of the patients who were not cyanosed at rest, 74 per cent. were talking by the age of eighteen months, and 84 per cent. by two years, whereas of the cyanosed patients the corresponding figures were 66 and 87 per cent. Of those with more severe cyanosis a slightly smaller proportion were talking at eighteen months, but only among those in whom severe cyanosis had been present since birth were fewer talking by two years than among the acyanotic group (table 7). Thus the majority of these patients began to talk at the normal age, and in those who started late, cyanosis can only have played a minor part. Although we have no other figures to prove it, we think that most of these children were of at least average mental capacity. Good school reports and winning of scholarships provide some evidence, but in the main this opinion must rest on our own judgment of these children, of whom we have seen much and talked with and about a great deal. Considering the low arterial oxygen saturation and often the diminished blood flow as well, it is a surprising finding, and is, we think, a striking example of the importance of inheritance compared with environment (deficiency of oxygen) in the development of intelligence. Taussig (1947) also states that extreme anoxaemia does not cause mental retardation. As a striking example, we quote the case of one boy of sixteen who could not write as he was one of our most severe cases and his parents had never had the heart to make him learn. On his typewriter, however, he produced a magazine containing news and stories that he had written, and circulated it among his relatives.

We think that such association as is found between congenital heart disease and mental defect is because these two defects are sometimes produced by the same genetic causes, and that congenital heart disease does not produce any mental defect or permanent backwardness, though when severe cyanosis is present from an early age there may be some delay in talking. This has an important practical corollary in that no parent should be allowed to think that the improvement in the child's general condition that may follow operation can be followed by any improvement in its mental capacity.

\section{Mental Deficiency and Mongolism}

Mental defect was sometimes responsible for the delay in talking. Out of the first $\mathbf{4 0 0}$ cases seen, seventeen were recognized as being mentally defective, over 4 per cent. compared with 1.5 per cent. of town children and 3 per cent. of rural children generally (Burt, 1937). At least ten other children were considered to be backward. Thus poor mental development could account for the delay in talking in 7 per cent. Of these twenty-seven patients, five were acyanotic, eighteen slightly or moderately, and four severely cyanosed. This proportion is not significantly different from that of the whole series, and the absence of any correlation with cyanosis supports the view that cyanosis is not responsible for the mental deficiency.

Five of these children were thought to be mongols. Benda (1946) gives a wealth of information about most aspects of mongolism but few details about the heart condition, except that 75 per cent. of these dying in infancy and 35 per cent. of those surviving have congenital heart disease. Brown (1939) says that 16-25 per cent. of mongols are so affected but does not say how many of his patients with congenital heart disease were mongols. Auricular septal defect is common in mongols, and according to Abbot (1927) and Brown (1939) especially those defects due to a persistent ostium primum where the anterior cusp of the mitral valve is often divided into two halves. Taussig (1947) thinks that there is often persistent atrio-ventricularis communis, a large sized auricular and a variable sized ventricular septal defect, often with the leaflets of the mitral and tricuspid valves fused to form a single atrioventricular valve and opening. This produces little cyanosis or clubbing, but four of our five patients were cyanotic and were thought to have Fallot's tetralogy or some closely related lesion.

Ross (1939) tested the intelligence quotient of twenty-two children with congenital heart disease and found that they were below the standard of the general out-patients there, only. 59 against 77 per cent. having an I.Q. over 70, and only 23 against 41 per cent. having an I.Q. of 91 or higher. These results are surprising, both as regards the large number of controls with an I.Q. under 70 and the children with congenital heart disease, especially as many of them had a patent ductus or a ventricular septal defect only. Ross concluded that the number studied was too small to exclude a chance difference, but that the children with congenital heart disease appeared to have a somewhat lower endowment as measured by the Binet-Simon tests. The absence of schooling may account for some of the difference.

These tests were carried out on very few of our children at first, only as a rule where some backwardness was suspected. Recently we have arranged for them more systematically, but from the early results we are doubtful if several of the tests used for assessing the intelligence quotient are reliable in distinguishing between the innate mental capacity and the educational standard in these children who have led such quiet lives at home and with so few outside contacts other than their parents.

We fully realize that we may have missed some of the more slightly mentally defective children and that some of the gravely affected ones may not have been brought to us either because they were already in institutions or for other reasons. We feel equally certain that most of our children were of good average intelligence and many seemed above this.

\section{Onset of Puberty}

We have no detailed figures about the onset of puberty, but think that it is frequently delayed in 
those with the more severe disability and cyanosis where the patient is most under weight.

\section{Deformity of the Chest}

Some deformity of the chest was seen in more than a third of these patients, in 136 of 332 in whom the chest was mentioned. The commonest of these deformities were pigeon chest (14 per cent.), Harrison's grooves or sulcus (16 per cent.), and prominence of the ribs (14 per cent.) usually on the left side but sometimes on the right side only or on both sides. Each was present in about fifty cases, and about a quarter of them had more than one deformity (table 8).

TABLE 8

TYPES OF CHEST DEFORMITY PRESENT IN 136 OF 332 PATIENTS WITH CONGENITAL HEART DISEASE

\begin{tabular}{lcc|ccc}
\hline & & \multicolumn{2}{c|}{ Severe } & Moderate & Slight \\
\hline Pigeon chest &. & 48 & 9 & 25 & 14 \\
Harrison's sulcus &.. & 52 & 5 & 13 & 34 \\
Prominence of ribs & 46 & On left & On right & Both \\
Others & & 33 & 5 & 8 \\
\hline
\end{tabular}

The incidence of deformity and of individual deformities in the patients with Fallot's tetralogy was very similar to that in patients with other lesions (table 9). This is rather surprising, as the former in general had not much cardiac enlargement and this is often thought to be a cause of such chest deformity. Most of them, however, had some hypertrophy of the right ventricle, and Taussig (1947) states that this developing at an early age is generally the cause of left-sided prominence of the chest.

The incidence among those with different degrees of disability and cyanosis was more variable (table 9), but the numbers are small and the variations inconsistent, making it difficult to draw any conclusions.

Prominence of the ribs, usually of the left side, was most striking in some of our cases, and that made the chest very asymmetrical. It was present twice as often in those with severe, as in those with less disability, but only slightly more in those with severe, than in those with little or no, cyanosis. This suggests that the deformity is related to the degree of disability and those with the greatest hypertrophy of the heart might be expected to be the most disabled. Right-sided prominence is less easy to explain. However, in one case dextrocardia was present and Taussig's explanation will again apply. In two others it was due to scoliosis.

Pigeon chest deformity and Harrison's sulcus seemed to show no significant correlation with disability or cyanosis so it is unlikely that these were a direct cause of the deformities.

Naish (1945) emphasized that Harrison's sulcus was found in congenital heart disease without rickets or chronic pulmonary disease. The incidence of Harrison's sulcus in our cases was much less than that found by Naish and Wallis (1948) in the congenital heart cases they examined, and indeed less than they found in normal children. Their paper is of much interest, not only for its rediscovery of Harrison's original description, but for the discussion of its mode of production. The abnormalities of the chest in our children was noted at the same time as the general examination which naturally concentrated on the heart, and minor deformities may well have been missed. But a check, where possible, on subsequent visits has shown that this was infrequent. Clearly Naish and Wallis, finding the deformity in 45 per cent. of

TABLE 9

PERCENTAGE OF CASES WITH VARIOUS CHEST DEFORMITIES, DIVIDED BY LESION, BY DISABILITY, AND BY CYANOSIS

Percentage* of Cases with

\begin{tabular}{|c|c|c|c|c|c|c|}
\hline & & & & & & \\
\hline & & & $\begin{array}{c}\text { Any } \\
\text { Deformity }\end{array}$ & $\begin{array}{l}\text { Pigeon } \\
\text { chest }\end{array}$ & $\begin{array}{l}\text { Harrison's } \\
\text { sulcus }\end{array}$ & $\begin{array}{c}\text { Prominence } \\
\text { of ribs }\end{array}$ \\
\hline Lesion & $\begin{array}{ll}\text { Fallot } & \ldots \\
\text { Others } & \ldots\end{array}$ & $\begin{array}{l}. \\
\cdots\end{array}$ & $\begin{array}{l}37 \\
36\end{array}$ & $\begin{array}{l}13 \\
10\end{array}$ & $\begin{array}{l}12 \\
12\end{array}$ & $\begin{array}{l}12 \\
15\end{array}$ \\
\hline Disability & $\begin{array}{l}\text { Severe .. } \\
\text { Moderate } \\
\text { Slight or nil }\end{array}$ & $\begin{array}{l}\because \\
\because \\
\cdots\end{array}$ & $\begin{array}{l}40 \\
40 \\
28\end{array}$ & $\begin{array}{l}11 \\
12 \\
15\end{array}$ & $\begin{array}{r}5 \\
15 \\
10\end{array}$ & $\begin{array}{l}21 \\
11 \\
10\end{array}$ \\
\hline Cyanosis & $\begin{array}{l}\text { Severe .. } \\
\text { Moderate } \\
\text { Nil .. }\end{array}$ & $\begin{array}{l}\cdots \\
\cdots \\
\cdots\end{array}$ & $\begin{array}{l}29 \\
40 \\
25\end{array}$ & $\begin{array}{r}7 \\
14 \\
9\end{array}$ & $\begin{array}{r}7 \\
15 \\
9\end{array}$ & $\begin{array}{l}14 \\
11 \\
11\end{array}$ \\
\hline
\end{tabular}

- These figures are given as a percentage of $\mathbf{4 0 0}$, the total number of cases seen, as it is considered that at least in the majority of the 63 cases in which the chest is not mentioned, deformity was trivial or not present. 
normal children, are dealing with a degree of the sukcus that is almost physiological and even their deeper groove of $\frac{3}{16}$ in. was present in nearly 7 per cent. They found Harrison's grooves in two-thirds of the patients with congenital heart disease and also refer to the marked indrawing of the lower intercostal spaces (at the same level as the sulcus) in some cases. We have noted this in an extreme form in some patients with large hearts.

Scoliosis was present in $\mathbf{2 5}$ of $\mathbf{4 0 0}$ cases excluding minor degrees of the condition. In four of these it was thought to be congenital and in two this was associated with hemi-vertebrae. In three cases it was extreme so that the heart was grossly displaced, and in one of these paraplegia developed from pressure on the cord (Case 0086).

Blalock (personal communication, 1947) suggested that unduly visible veins over the chest wall were common and were some indication of the extent of the collateral circulation likely to be found at operation. We have, therefore, looked for them and recorded their presence. They were seen, especially over the upper half of the front of the chest, but were often present on the scalp and face of the smaller children, and in the fingers and hands of those with severe clubbing. Sometimes the fingers have a most curious appearance, the dusky hue and dilated veins extending beyond the terminal phalanx so that at times the parents say the ends of the fingers go almost black. Occasionally the dilated veins are more generalized.

Dilated or unduly prominent veins were noted in 107 cases, and their absence in 198 . Cyanosis was present in the majority of these with dilatation, and the more severe the cyanosis the greater it tended to be. Thus among the acyanotic patients only 11 per cent. showed this dilatation and it was slight in three-quarters of them; while among the less severely cyanosed patients 30 per cent. showed it and in half of them it was considerable. Among those with severe cyanosis dilatation was present in 37 per cent., and of considerable degree in more than three-quarters.

\section{Summary}

Some aspects of the physical and mental development of $\mathbf{4 0 0}$ children with congenital heart disease, mainly cyanotic, have been discussed, and 200 cases where the data were complete have been analysed more fully as regards their height and weight. Fallot's tetralogy was the diagnosis made most commonly; this, or some closely related lesion, was present in nearly half of all the cases, and in twothirds of those who were cyanotic.

The children were, on the whole, slightly below the expected height for their age, and the average figure was 96 per cent. of the normal. This means that a child of one year was more than 1 in. below, and a young adult 21 in. below, the average.

The weight was much more below standard than the height so that the children looked thin, and the average figures was as low as 85 per cent. of the expected normal. Eight-tenths of them were more than $2 \mathrm{lb}$. below the average weight and only one-tenth were this amount above it.

Comparison of the height and weight showed that they were below the expected weight for their height as well as below the expected weight for their age.

Both as regards height and weight, those who had severe cyanosis were more below the expected level than those who had moderate cyanosis, and still more below those who were acyanotic. Those who were diagnosed as cases of Fallot's tetralogy were less below height and weight than the other comparably cyanotic cases.

The ages of walking and talking were taken as measures of their general development. There was some delay among the cyanotic cases and only 73 per cent. of them were walking by the age of two years. When there was severe cyanosis that dated from birth less than half (47 per cent.) were walking by the age of two years; but great delay was not found, and where children are not walking by the age of three years other causes must be looked for.

There was less delay in the age of talking, but here, too, among those who had been severely cyanosed from birth, a smaller proportion were talking by eighteen months, though by two years of age this delay had almost been overcome.

We thought that the mental capacity of these children was normal and well up to the average, though many were educationally backward. There were 4 per cent. who were defective, a larger proportion than among children in general, but, partly because of the good normal development of the others, we think this was a second associated defect rather than a direct effect of the cyanosis and anoxaemia.

Among these cases there were five mongols and four of them were cyanotic, though auricular septal defects, which do not as a rule produce cyanosis, are recognized as the commonest congenital heart defect in mongols.

Some chest deformity was present in many of these children; about 15 per cent. showed pigeon chest, 15 per cent. Harrison's sulcus, and 15 per cent. some prominence of the ribs, generally on the left side. Scoliosis was not uncommon and was occasionally severe, and this and some other deformities of posture had often been made worse by squatting.

We wish to thank Dr. P. R. Evans for his advice regarding the milestones of children's development, though he must not be held responsible for the standards we have finally adopted. 


\section{References}

Abbot, M. E. (1927). 'Osler's Modern Medicine' 4, 612. London.

Baker, C., Brock, R. C., Campbell, M., and Suzman, S. (1949). Brit. Heart J., 11, 170.

Bedford, D. E., Papp, C., and Parkinson, J. (1941). Brit. Heart J., 3, 37.

Benda, C. E. (1946). 'Mongolism and Cretinism.' Grune and Stratton. New York.

Benn, J. (1947). Brit. Heart J., 9, 283.

Bramwell, C. (1947). Brit. Heart J., 9, 100.

Brown, J. W. (1939). 'Congenital Heart Disease.' John Bale, Ltd. London.

Burt, C. (1937). 'Backward Child.' University of London Press.
Cruickshank, E. W. H. (1946). ' Food and Nutrition.' Livingstone. Edinburgh.

Holt, L. E., and McIntosh, R. (1940). 'Holt's Disease of Infancy and Childhood.' Appleton Century Crofts. New York.

Menzies, F. (1940). 'Report on the Average Heights and Weights of Elementary School Children in the County of London in 1938 .

Naish, A. E. (1945). Arch. Dis. Childh., 20, 185.

Naish, J., and Wallis, H. R. E. (1948). Brit. med. J., 1,541 .

Newman, M. (1948). Brit. Heart J., 10, 150.

Perlman, L. (1944). Amer. Heart J., 28, 24.

Roesler, H. (1934). Arch. intern. Med.. 54. 339.

Ross, M. (1939). J. Pediat., 14, 21.

Taussig, H. B. (1947). "Congenital Malformations of the Heart.' Commonwealth Fund. New York. 